RESEARCH PAPER

\title{
Designated "no smoking" areas provide from partial to no protection from environmental tobacco smoke
}

\author{
T Cains, S Cannata, R Poulos, M J Ferson, B W Stewart
}

Tobacco Control 2004;13:17-22. doi: 10.1136/tc.2003.005488

See end of article for authors' affiliations

Correspondence to: Professor Bernard

W Stewart, South East Sydney Public Health Unit, Locked Bag 88, Randwick NSW 2031 Australia; stewartb@sesahs.nsw. gov.au

Received 29 July 2003 Accepted 21 October 2003
Objective: To determine the efficacy of designated "no smoking" areas in the hospitality industry as a means of providing protection from environmental tobacco smoke (ETS), and whether certain design features assist in achieving this end.

Methodology: In the greater metropolitan region of Sydney, a representative group of 17 social and gaming clubs, licensed to serve alcoholic beverages and in which, apart from designated areas, smoking occurs, agreed to participate. In each establishment, simultaneous single measurements of atmospheric nicotine, particulate matter (10 $\mu \mathrm{m}$; PM10) and carbon dioxide $\left(\mathrm{CO}_{2}\right)$ levels were measured in a general use area and in a designated "no smoking" area during times of normal operation, together with the levels in outdoor air (PM10 and $\mathrm{CO}_{2}$ only). Analyses were made of these data to assess the extent to which persons using the "no smoking" areas were protected from exposure to ETS.

Results: By comparison with levels in general use areas, nicotine and particulate matter levels were significantly less in the "no smoking" areas, but were still readily detectable at higher than ambient levels. For nicotine, mean (SD) levels were $100.5(45.3) \mu \mathrm{g} / \mathrm{m}^{3}$ in the areas where smoking occurred and 41.3 (16.1) $\mathrm{\mu g} / \mathrm{m}^{3}$ in the "no smoking" areas. Corresponding PM10 levels were $460(196) \mu \mathrm{g} / \mathrm{m}^{3}$ and 210 (210) $\mu \mathrm{g} / \mathrm{m}^{3}$, while outdoor levels were $61(23) \mu \mathrm{g} / \mathrm{m}^{3}$. The reduction in pollutants achieved through a separate room being designated "no smoking" was only marginally better than the reduction achieved when a "no smoking" area was contiguous with a smoking area. $\mathrm{CO}_{2}$ levels were relatively uninformative.

Conclusion: Provision of designated "no smoking" areas in licensed (gaming) clubs in New South Wales, Australia, provides, at best, partial protection from ETS-typically about a 50\% reduction in exposure. The protection afforded is less than users might reasonably have understood and is not comparable with protection afforded by prohibiting smoking on the premises.
$\mathrm{T}$ he source, composition, and hazardous nature of environmental tobacco smoke (ETS) are well recognised. ${ }^{1-4}$ In respect of cancer causation, the International Agency for Research on Cancer recently determined that ETS is appropriately categorised as a group 1 carcinogen-that is, ETS is established as causing cancer in humans. It is an accepted principle of public health that humans should not knowingly be exposed to recognised carcinogens in circumstances where such exposure is effectively preventable. Eliminating, or minimising, exposure is generally achieved by changes in practice and behaviour and, where practicable, encouraging or mandating the requisite change by legislation or similar procedure. ${ }^{5}$ In respect of exposure to ETS in the workplace, change has been motivated by the award of damages to employees against employers in relation to disease attributable to ETS. Specifically, in Australia, damages were so awarded in respect of laryngeal cancer suffered by a barmaid. ${ }^{6}$ For the hospitality industry in particular, where there is a perception that a prohibition on smoking might reduce patronage, an attractive option has been the designation of "no smoking" areas. The practice is widespread, and common experience indicates great variation in the manner in which such areas are configured. At one extreme, specific rooms may be identified as "no smoking". At the other extreme, space defined only with reference to arbitrary and often approximate boundaries, in an otherwise continuous expanse, may be designated a "no smoking" area.

The extent to which designated "no smoking" areas provide protection from tobacco may be anticipated to vary according to their configuration. ${ }^{7}$ That said, modelling studies indicate that such areas will not provide complete protection from ETS. ${ }^{1}$ In respect of monitoring levels of ETS, an inference of reduced exposure may be made from some studies. A brief Japanese report of a "practical and low cost" non-smoking area established in an office using screens resulted in improved air quality (by survey) and decreased suspended particulates. ${ }^{8}$ A study based on 25 diverse worksites (principally manufacturing facilities) recorded nicotine concentrations which fell from a median of $8.6 \mu \mathrm{g} / \mathrm{m}^{3}$ in open office where smoking was allowed, to $1.3 \mu \mathrm{g} / \mathrm{m}^{3}$ at sites that restricted smoking to $0.3 \mu \mathrm{g} / \mathrm{m}^{3}$ in worksites where smoking was banned. ${ }^{9}$ Likewise, inference may be made from two studies in restaurants that some reduction in exposure is achieved as a consequence of being located in the "no smoking" section. ${ }^{10}{ }^{11}$

While the studies summarised above provide some inference that designated "no smoking" areas may provide protection from ETS, the relatively scant data do not allow a clear understanding of the extent of such protection, and any design limitations on achieving it. There are some indications that in bars, nightclubs, and gaming venues, levels of ETS are among the highest recorded. ${ }^{12}$ We report here a study undertaken in "licensed clubs" in Sydney, New South Wales, Australia: premises licensed to sell alcoholic beverages for consumption on the premises and which provide gaming machines as a principal recreation for patrons. In the premises studied, the "no smoking" areas involved either designation of specific rooms as "no smoking" or areas

Abbreviations: ETS, environmental tobacco smoke; OS, one space; SR, separate room 
within an otherwise single space were designated as "no smoking". Levels of nicotine, particulates, and carbon dioxide $\left(\mathrm{CO}_{2}\right)$ were determined in such areas and contrasted with those levels in other indoor spaces where smoking occurred and also with the outside air. Though the present investigation was limited in some respects, the data now available indicate that designated "no smoking" areas, regardless of their configuration, provide only partial protection from tobacco smoke at best. At worst, the data suggest that no protection whatsoever is afforded by the measures in question.

\section{METHODS}

A list of potential participants in the study, covering "clubs" catering to diverse interests (including football, lawn bowling, golf, veterans, social and community improvement clubs) was generated from the telephone directory. Club managers were then contacted and asked to participate in an interview in which the principles and mechanics of the project were delineated. None of the clubs so approached subsequently declined an invitation to participate in the study, and the process of contacting clubs ceased when the number of clubs agreeing to participate reached 17. All managers expressed the wish that their clubs' identity and participation in the study not be made public.

Following agreement to participate, a questionnaire was sent to each club. Details were requested concerning the configuration of designated "no smoking" areas in relation to similar spaces in which smoking occurred. The designated "no smoking" area of each club was categorised according to whether such facilities involved provision of a room in which smoking was not permitted, or the identification of a subsection of a room as a "no smoking" area. In general, smoking occurred in all interior spaces of each club apart from the designated "no smoking" areas. In respect of those clubs in which a separate room was designated "no smoking", sufficient data were obtained to allow the ventilation system in such a room to be characterised as independent of that responsible for ventilating other space, or a common ventilation system was involved. Of those clubs having separate rooms, only three had separate ventilation systems. Preliminary evaluation of the data showed no clear difference between results according to the type of ventilation system. Accordingly, data for the "separate rooms" configuration were treated as a single group irrespective of the type of ventilation system.

For each facility, in the designated "no smoking" area and in an area where there was no such restriction, determinations of atmospheric levels of nicotine, particulate matter $(10 \mu \mathrm{m})(\mathrm{PMl})$ ), and $\mathrm{CO}_{2}$ were made; PMI0 and $\mathrm{CO}_{2}$ levels were also measured outdoors. Measurements were undertaken at a time of maximal occupancy as advised by management of each facility. Typically, this was a Friday evening. In all instances, analytical equipment was located centrally and remote from ventilation related fixtures in the ceiling. In the "no smoking" areas, equipment was positioned equi-distant from doorways. Measurements in a space where smoking occurred were undertaken in a high traffic area, namely in the room in which gaming machines were located. Outdoor determinations at each facility were undertaken in an area adjacent to the club building, but remote from human or vehicular traffic and from ventilation fixtures.

Nicotine levels were measured using a passive sampler (CSIRO Division of Atmospheric Research, Aspendale, Victoria, Australia) based on the principle of molecular diffusion of a gas onto a filter with a sorbent species, integrated over the time of exposure. ${ }^{13}$ The samplers require an optimal collection period of six hours. Two samplers were employed at each facility: one located in the smoking and the other in the "no smoking" area of the club as previously described, and each positioned at least $1.5 \mathrm{~m}$ above floor level.

PM 10 levels were determined using a DUSTRAK Aerosol Monitor (Model 8520, TSI, Minneapolis, Minnesota, USA) with a cut-point for particles less than $10 \mu \mathrm{m}$ programmed to log every 30 seconds. Ten minute samples were taken in each of the smoking, "no smoking", and outdoor areas.

Carbon dioxide levels were measured simultaneously using a TSI Q-Trak Indoor Air Monitor (Model 8551), programmed to $\log$ every 30 seconds. Samples were taken in the same manner as indicated for the PMI0 determinations.

All data collected from the TSI Dustrak and the TSI Q-Trak were downloaded each day into the Trak Pro software program. The nicotine samplers were analysed blind by the CSIRO Atmospheric Research Branch.

Data were expressed as mean (SD). Missing data on nicotine levels occurred for the smoking area of one club, and the non-smoking area of another club. These clubs have been excluded from comparative analysis of nicotine levels. Differences between determinations for particular room configurations were tested using the independent samples $t$ test; differences between smoking and "no smoking" areas and between "no smoking" and outside areas were tested using the paired samples $t$ test.

\section{RESULTS}

Information concerning each participating club is summarised in table 1 . The estimated number of patrons in the areas where smoking occurred and which were designated "no smoking" were made on the basis of observations during the sampling period. No person was observed to be smoking in any of the designated "no smoking" areas during the observation period.

\section{Nicotine}

Pronounced variation in levels of nicotine recorded was evident in both the smoking and designated "no smoking" areas of the respective clubs. In all clubs, the concentration of nicotine in the "no smoking" area was less than in the corresponding smoking area (fig 1).

The mean (SD) concentration of nicotine in the designated "no smoking" areas was $41.4(16.1) \mu \mathrm{g} / \mathrm{m}^{3}$ and the mean level in the areas where smoking occurred was 100.5 (45.3) $\mu \mathrm{g} / \mathrm{m}^{3}$ ( $\left.\mathrm{n}=16\right)$.

In clubs where the "no smoking" area was a separate room (such facilities being designated "SR"), the mean nicotine level in the "no smoking" area was $35.8(10.7) \mu \mathrm{g} / \mathrm{m}^{3}$, compared to a level of $83.2(24.2) \mu \mathrm{g} / \mathrm{m}^{3}$ in the smoking areas, the difference being significant $(\mathrm{p}<0.0005)$. In those clubs where the designated "no smoking" area was a subsection of a room where smoking otherwise occurred (one space facilities, designated "OS"), the mean level of nicotine in the "no smoking" area was 54.9 (19.4) $\mu \mathrm{g} / \mathrm{m}^{3}$ compared with $143.1(54.3) \mu \mathrm{g} / \mathrm{m}^{3}$ in the area where smoking took place $(p<0.05)$. Thus the atmospheric concentration of nicotine in both the smoking and non-smoking areas of facilities in the OS category were slightly, but not significantly, greater than levels in the corresponding areas of the SR facilities.

To evaluate the protection from tobacco smoke that could be achieved by moving from a smoking area to a "no smoking" area, the per cent reduction in nicotine level was calculated as follows: \% reduction $=$ [nicotine level (smoking) - nicotine level (no smoking)]/nicotine level (smoking).

Taking results for all facilities into account, an individual could expect, on average, to achieve a 53\% (median 63\%, 


\begin{tabular}{|c|c|c|c|c|c|c|}
\hline $\begin{array}{l}\text { Club } \\
\text { number }\end{array}$ & Club type & $\begin{array}{l}\text { Smoking room } \\
\text { or } \\
\text { area }\left(\mathrm{m}^{2}\right)\end{array}$ & $\begin{array}{l}\text { "No-smoking" } \\
\text { room or area }\left(\mathrm{m}^{2}\right)\end{array}$ & $\begin{array}{l}\text { Club } \\
\text { membership }\end{array}$ & $\begin{array}{l}\text { Estimated number of patrons } \\
\text { during sampling in smoking } \\
\text { room or area }\end{array}$ & $\begin{array}{l}\text { Estimated number of patrons } \\
\text { during sampling in "no smoking" } \\
\text { room or area }\end{array}$ \\
\hline 1 & Social & 150 & 60 & 28000 & 120 & 15 \\
\hline 2 & Football & 800 & 250 & 46100 & 80 & 80 \\
\hline 3 & RSL & 300 & 100 & 6000 & 50 & 10 \\
\hline 4 & Social & 400 & 100 & 28000 & 150 & 60 \\
\hline 5 & Social & 100 & 200 & 35000 & 35 & 30 \\
\hline 6 & Social & 250 & 60 & 6300 & 80 & 10 \\
\hline 7 & Golf & 120 & 300 & 4800 & 25 & 65 \\
\hline 8 & Football & 350 & 180 & 33000 & 80 & 60 \\
\hline 9 & Football & 450 & 200 & 48500 & 100 & 10 \\
\hline 10 & Veterans & 350 & 200 & 2000 & 60 & 40 \\
\hline 11 & Veterans & 250 & 300 & 7900 & 70 & 50 \\
\hline 12 & Social & 350 & 200 & 9200 & 90 & 15 \\
\hline 13 & Veterans & 250 & 120 & 2000 & 40 & 10 \\
\hline 14 & Football & 200 & 100 & 10000 & 120 & 60 \\
\hline 15 & Veterans & 450 & 200 & 8200 & 300 & 40 \\
\hline 16 & Veterans & 450 & 130 & 8000 & 120 & 80 \\
\hline 17 & Bowling & 90 & 100 & 4000 & 15 & 10 \\
\hline
\end{tabular}

range $12-86 \%$ ) reduction in nicotine level by relocating from the smoking to the "no smoking" area (table 2). The mean per cent reduction of $53 \%$ was similar for SR facilities (median $63 \%$, range $15 \%-75 \%$ ) as for OS facilities where the mean reduction was $55 \%$ (median $60 \%$, range $12 \%-86 \%$ ).

\section{Particulate matter (PM 10)}

In all clubs but two (clubs 15 and 17), the PMI0 levels in designated "no smoking" areas were less than those which prevailed in smoking areas. However, except for one club (club 1), PM10 levels recorded inside were invariably greater than the "outdoors" determination (fig 2).

The mean PMIO level in outdoors-that is, in an open area remote from vehicle or human traffic or any ventilation plant—was 61 (23) $\mu \mathrm{g} / \mathrm{m}^{3}$. The mean indoor levels were higher and subject to wide variation as are readily evident from the mean of $210(210) \mu \mathrm{g} / \mathrm{m}^{3}$ for "no smoking" areas and $460(197) \mu \mathrm{g} / \mathrm{m}^{3}$ for smoking areas. The difference in PM10 levels between smoking and "no smoking" areas was significant $(\mathrm{p}<0.01)$ as was the difference between PM10 levels in "no smoking" and outdoors $(\mathrm{p}<0.05)$.

A distinction was evident between PM10 levels in the "no smoking" areas of SR compared to OS facilities. In SR premises, the mean PMI0 level was $129(76) \mu \mathrm{g} / \mathrm{m}^{3}$ in "no smoking" compared to 421 (191) $\mu \mathrm{g} / \mathrm{m}^{3}$ in smoking areas $(\mathrm{p}<0.0005)$. By contrast, in OS premises, the mean PMI0 level of 404 (307) $\mu \mathrm{g} / \mathrm{m}^{3}$ for "no smoking" areas was not significantly different from the level of $555(197) \mu \mathrm{g} / \mathrm{m}^{3}$ in smoking areas.

With the exception of one facility, PM10 levels in designated "no smoking" areas were greater than PMI0 levels outdoors. The difference was significant in the case of SR facilities $(p<0.05)$ and approached significance in the case of OR clubs $(\mathrm{p}=0.068)$.

Using the same formula as specified for per cent reduction in nicotine levels (see above), in respect of all determinations taken together, an individual could expect, on average, to achieve a $52 \%$ reduction (median $59 \%$, range $-40 \%$ to $87 \%$ ) in PM10 levels by relocating from the smoking to the "no smoking" area of the clubs. The mean reduction was $66 \%$ (median $67 \%$, range $37-87 \%$ ) for SR facilities but only $17 \%$ (median $4 \%$, range $-40 \%$ to $82 \%$ ) for Os facilities. Moving outside achieved a mean $85 \%$ reduction (median $85 \%$, range 73-95\%) in PMl0 levels compared to the PMl0 levels of smoking areas of clubs.

\section{Carbon dioxide}

Differences were modest between $\mathrm{CO}_{2}$ determinations variously made within smoking and "no smoking" areas, and at outdoor locations (fig 3).

The mean (SD) $\mathrm{CO}_{2}$ levels across all clubs were 600 (94) parts per million (ppm) outdoors, 872 (159) ppm in the "no smoking" areas and 849 (135) ppm in the smoking areas. There was no significant difference between levels in the smoking and "no smoking" areas. $\mathrm{CO}_{2}$ levels indoors were significantly higher than outdoor levels $(\mathrm{p}<0.0005)$.

\section{DISCUSSION}

As indicated earlier, the present study was undertaken as an initial approach to the evaluation of protection from ETS afforded by designated "no smoking" areas, particularly in the hospitality industry. While certain conclusions may be

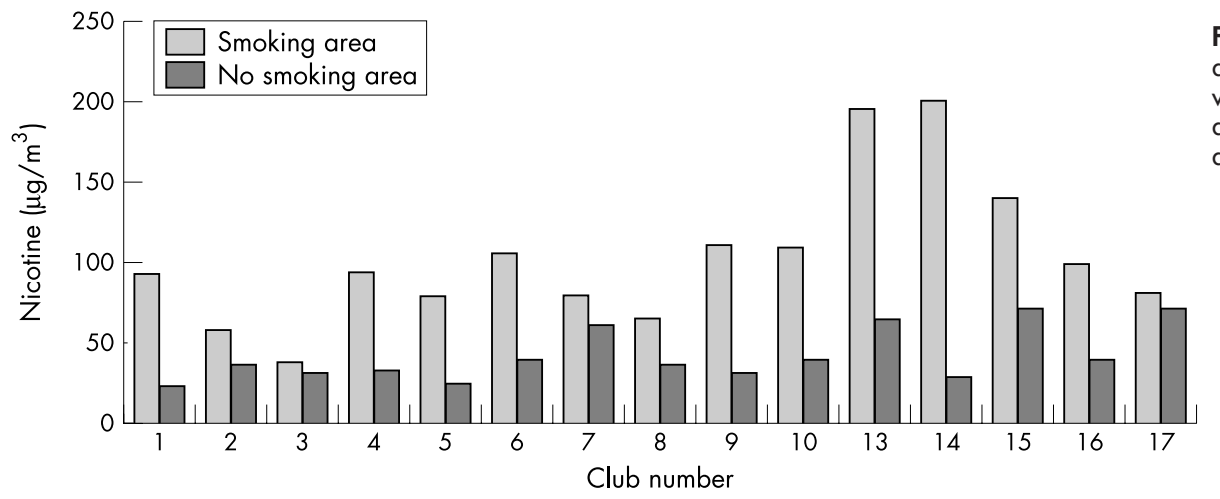

Figure 1 Concentration of atmospheric nicotine in clubs: smoking versus "no smoking" areas*. *Clubs 11 and 12 excluded because of missing data. 


\begin{tabular}{|c|c|c|c|c|}
\hline Club number & $\begin{array}{l}\text { Type of } \\
\text { space }\end{array}$ & $\begin{array}{l}\text { Smoking area } \\
\text { nicotine level } \\
\left(\mu \mathrm{g} / \mathrm{m}^{3}\right)\end{array}$ & $\begin{array}{l}\text { No-smoking area } \\
\text { nicotine level }\left(\mu \mathrm{g} / \mathrm{m}^{3}\right)\end{array}$ & $\begin{array}{l}\% \text { reduction in atmospheric } \\
\text { nicotine level from smoking } \\
\text { to no-smoking area }\end{array}$ \\
\hline 1 & SR & 93.1 & 23.3 & 75.0 \\
\hline 2 & SR & 57.4 & 36.2 & 36.9 \\
\hline 3 & SR & 37.5 & 31.8 & 15.2 \\
\hline 4 & SR & 94.2 & 33.6 & 64.3 \\
\hline 5 & SR & 79.6 & 25.0 & 68.6 \\
\hline 6 & SR & 106.4 & 39.4 & 63.0 \\
\hline 7 & SR & 79.0 & 61.8 & 21.8 \\
\hline 8 & SR & 65.2 & 35.6 & 45.4 \\
\hline 9 & SR & 110.6 & 31.0 & 72.0 \\
\hline 10 & SR & 109.1 & 39.8 & 63.5 \\
\hline 11 & SR & 59.9 & - & - \\
\hline 12 & SR & - & 29.6 & - \\
\hline 13 & OS & 195.7 & 63.8 & 67.4 \\
\hline 14 & OS & 199.7 & 28.7 & 85.6 \\
\hline 15 & OS & 140.3 & 71.1 & 49.3 \\
\hline 16 & OS & 98.7 & 39.9 & 59.6 \\
\hline 17 & OS & 81.0 & 71.0 & 12.4 \\
\hline
\end{tabular}

drawn from the analyses undertaken, there are clear limitations by dint of study design. The study involved single measurements at each location. The one similar study (involving nicotine and particulate determinations at seven restaurants) involved two determinations in each location. ${ }^{10}$ Single measurements are insufficient to definitively establish the situation at a specific location: the present study was relatively more expansive concerning the number of locations. That said, the study involved "licensed clubs" (a term previously explained) drawing upon different sectors of the community. The clubs involved included sporting, cultural, general entertainment, and community service backgrounds. However, no inferences may be drawn in respect of differences attributable to or correlated with particular types of clubs. No attempt has been made in this study to relate levels of smoking derived contaminants to the size of occupied spaces, or the number of people present. In relation to the latter, it was evident that available technology required analysis of nicotine in particular to be conducted over a period of several hours during which change in number of occupants was inevitable.

In the study now reported, differentiation was made between "no smoking" facilities that involved separate rooms being nominally smoke-free (the SR scenario) and those in which an area in an otherwise single space was designated "no smoking" (the OS scenario). In respect of the SR locations, initial data recorded by us included whether the respective "smoking" and "no smoking" rooms had separate or common ventilation systems. It was determined that only three of the facilities had separate ventilation systems. Preliminary assessment indicated that the data from these three locations were not notably different from the other SR data, and in consequence no attempt was made to make inferences in relation to ventilation systems.

In respect of the limitations identified, it is evident that a more comprehensive study might involve multiple analyses being undertaken at each location and further sub-categorisation of the facilities. Possible relations between numbers of persons present, the size of the space occupied, and the level of tobacco smoke derived pollution might be addressed.

Determination of the extent of occupational and related exposure to ETS have typically involved contrast between situations in which smoking is either permitted or prohibited. ${ }^{14}$ Despite such extremes, attempts to prevent exposure to ETS in public places and/or places of employment have specifically included the designation of "no smoking areas" within premises where smoking is otherwise permitted. Few, if any, data are available to determine the efficacy of this measure to reduce or prevent exposure to tobacco smoke.

In the present context, ETS is virtually the only source of atmospheric nicotine. The relevant measurements indicate some reduction in the level of exposure to tobacco smoke is achieved by being in a designated "no smoking area" rather than where smoking is permitted: there is significant

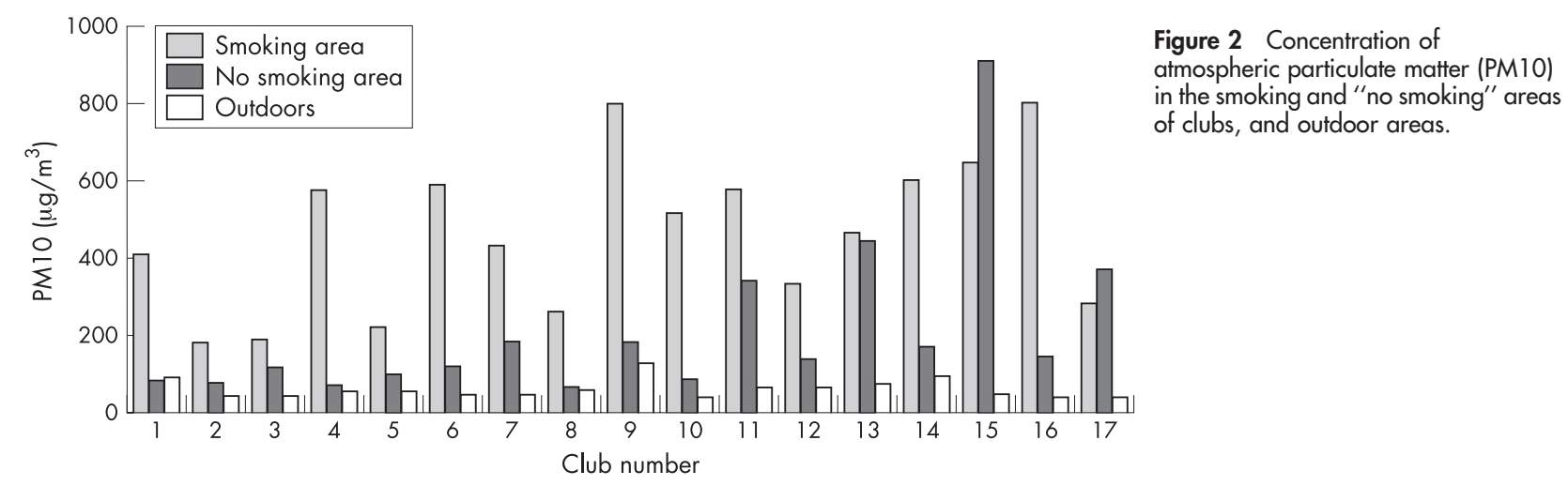




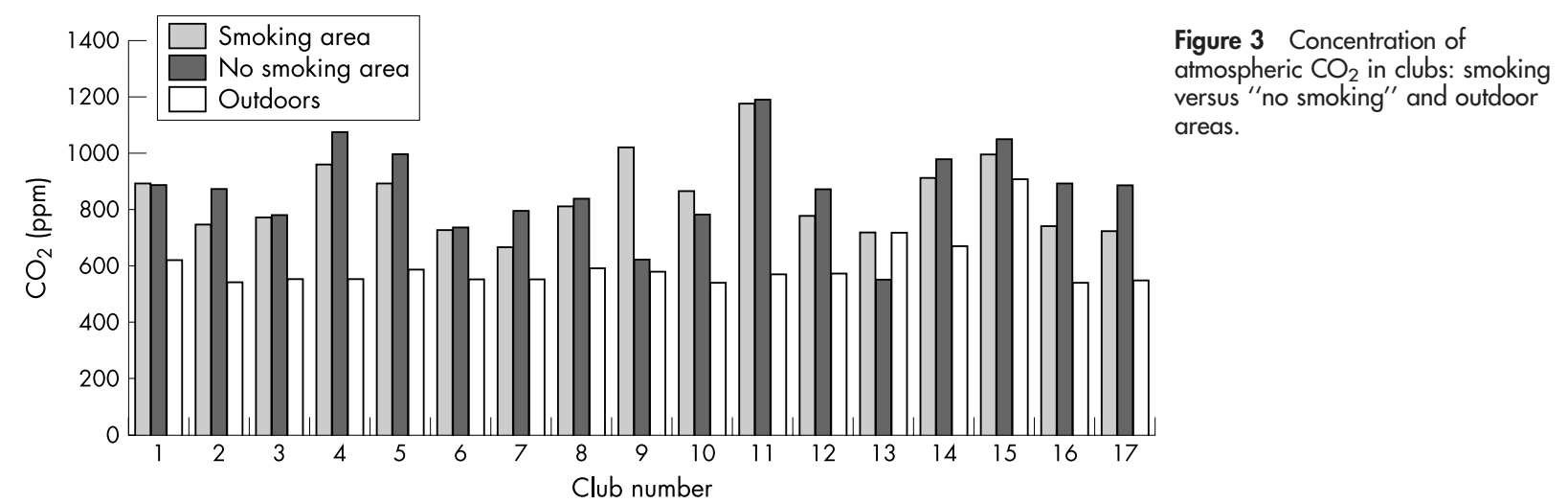

difference between the mean values. Reduced levels of atmospheric nicotine were apparent in both the configurations examined in this study: the provision of a separate room or the simple designation of an area as "no smoking" within a larger space where smoking occurs. Although data are limited, the hazard presented by passive smoking appears to be dose dependent, ${ }^{15}$ and therefore any reduction in exposure is arguably a positive development. That said, and irrespective of the particular configuration of "no smoking" area under consideration, the per cent reduction achieved by relocating from a smoking area to a non-smoking area should not be presumed to be anything better than a $50 \%$ reduction on average. Moreover, the wide extent of variation, including individual site per cent reduction values of less than $20 \%$ for both SR and OS configurations (table 2), caution against a presumption of any biologically significant outcome from such relocation.

Particulate matter of the type measured in this investigation is not uniquely sourced to tobacco smoke. As it occurs outdoors, such particulate matter is an indicator of air pollution and, among other sources, is derived from engine emissions. ${ }^{16}$ On the other hand, cigarette smoke is the preeminent source of such particulate matter as it pollutes the indoor atmosphere. Moreover, in respect of being generated as a result of burning tobacco, particulate matter may be directly related to the carcinogenic activity of tobacco smoke as a major vehicle of inhaled polycyclic aromatic hydrocarbons. $^{312}$ In the first instance, our determination of particulates confirmed the inference arising from atmospheric nicotine measurements-namely, that designated "no smoking" areas fail to provide protection from ETS. The data are more complicated, insofar as nicotine does not occur in outdoor air, but particulates do. With a single exception, the outdoor PM10 levels were less than either of the values areas measured indoors-that is, in the "smoking" and "no-smoking" areas (fig 2). The differences were significant; in particular, the mean PMI0 levels outdoors were significantly less than those in the designated "no smoking" areas, indicating that occupancy of the latter resulted in greater exposure than would have been achieved by going outside.

Determination of PM10 levels provided distinction between the two configurations of "no smoking" areas under consideration-SR and OS. Provision of a separate "no smoking" room resulted in significantly lower particulate levels by comparison to those in the corresponding smoking areas. However, the identification of a "no smoking" area within a larger room or space where smoking was otherwise permitted cannot be presumed to result in a significant reduction in exposure to particulate matter than that occurring were an individual to remain in that area where smoking is allowed (table 3). Such a consequence of the different configurations is also reflected in the corresponding "per cent reduction". Thus, in contrast to an average $66 \%$ reduction achieved from relocating from smoking to "no smoking" areas in an SR situation, simply moving from that

\begin{tabular}{|c|c|c|c|c|c|c|}
\hline Club number & $\begin{array}{l}\text { Type of } \\
\text { space }\end{array}$ & $\begin{array}{l}\text { Smoking } \\
\text { area PM10 } \\
\left(\mu \mathrm{g} / \mathrm{m}^{3}\right)\end{array}$ & $\begin{array}{l}\text { No-smoking area } \\
\text { PM10 }\left(\mu \mathrm{g} / \mathrm{m}^{3}\right)\end{array}$ & $\begin{array}{l}\text { Outdoor area } \\
\text { PM10 }\left(\mu \mathrm{g} / \mathrm{m}^{3}\right)\end{array}$ & $\begin{array}{l}\% \text { reduction in PM10 from } \\
\text { smoking to non-smoking } \\
\text { area }\end{array}$ & $\begin{array}{l}\text { \% reduction in PM10 from } \\
\text { smoking to outdoor area }\end{array}$ \\
\hline 1 & SR & 409 & 83 & 93 & 80 & 77 \\
\hline 2 & SR & 185 & 76 & 44 & 59 & 76 \\
\hline 3 & SR & 187 & 117 & 48 & 37 & 74 \\
\hline 4 & SR & 569 & 72 & 58 & 87 & 90 \\
\hline 5 & SR & 223 & 99 & 61 & 56 & 73 \\
\hline 6 & SR & 586 & 115 & 45 & 80 & 92 \\
\hline 7 & SR & 430 & 179 & 48 & 58 & 89 \\
\hline 8 & SR & 260 & 67 & 61 & 74 & 77 \\
\hline 9 & SR & 790 & 179 & 126 & 77 & 84 \\
\hline 10 & SR & 512 & 87 & 41 & 83 & 92 \\
\hline 11 & SR & 569 & 337 & 64 & 41 & 89 \\
\hline 12 & SR & 332 & 135 & 64 & 59 & 81 \\
\hline 13 & OS & 458 & 439 & 73 & 4 & 84 \\
\hline 14 & OS & 595 & 169 & 88 & 72 & 85 \\
\hline 15 & OS & 646 & 904 & 47 & -40 & 93 \\
\hline 16 & OS & 798 & 141 & 39 & 82 & 95 \\
\hline 17 & OS & 278 & 368 & 38 & -32 & 86 \\
\hline
\end{tabular}


What this paper adds

Within the hospitality industry in particular, designation of rooms or parts of rooms as "no smoking", in premises where smoking otherwise occurs, is common. Thus, for example, in clubs licensed to sell alcohol for consumption on the premises and providing gaming machines as a principal recreation, and which are located in metropolitan Sydney, Australia, such "no smoking" facilities are offered. Data regarding the protection from environmental tobacco smoke (ETS), which is afforded to club patrons taking advantage of these facilities, are extremely limited. We have sought to evaluate the extent of protection by monitoring levels of ETS related pollutants in smoking and "no smoking" areas of such licensed clubs.

Levels of atmospheric nicotine and tobacco related particulates determined in smoking, "no smoking", and outdoor areas of 17 licensed clubs around Sydney indicate that designated "no smoking" areas do not provide complete protection from ETS. Some reduction in exposure is evident, and separate rooms are in some respects an improvement upon simply delineating a "no smoking" area in a smoking room. However, club patrons might typically expect no more than a $50 \%$ reduction in exposure by having recourse to these "no smoking" areas. In some instances, no reduction was evident. Accordingly, such areas cannot be characterised as "smoke-free" and patrons occupying these areas do not achieve the protection from ETS they would experience were smoking not to occur on the premises.

part of the room to another identified with "no smoking" signs resulted in an almost trivial average reduction (17\%) in exposure. Indeed, in two individual situations, the PMI0 levels were actually higher in such "no smoking" spaces, a scenario not observed in the SR clubs (table 3).

The measurement of $\mathrm{CO}_{2}$ levels, while indicating differences between outdoor and indoor levels (fig 3), did not allow for further inferences concerning the efficacy of designated "no smoking" areas than could be drawn from nicotine and particulate measurements.

Walsh and Tzelepis ${ }^{17}$ have recently reviewed support for smoking restrictions evident from relevant studies involving bars and gaming areas in Australia. In their review, what are described as designated "no smoking" areas in the present report have been variously described in other studies as "separate areas", "restricted areas", "special areas", and "smoke-free areas". The respective terms were employed in studies, but any of them might be employed more widely. All of these epithets are reasonable, except the last one. It is clear from the present studies that the use in any context of the term "smoke-free area" to identify where, as distinct from practice elsewhere in that same building, smoking is not permitted, is incorrect. On the basis of atmospheric contamination as recorded by us, the use of the term "smoke-free

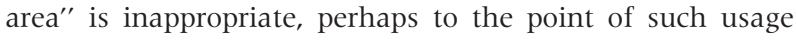
now being misleading and deceptive.

The present results indicate that designated "no smoking" areas may provide some reduction in the level of exposure of individuals to ETS. However, such areas clearly do not eliminate exposure to ETS, and the reduction achieved may be marginal or trivial. Occupying a separate room designated "no smoking" offers, at best, a marginal improvement in the protection afforded from ETS achieved by being in a "no smoking" area which is part of a room where smoking occurs everywhere else. At least, however, by having recourse to a separate "no smoking" room, an individual would not be worse off. In respect of "no smoking" areas in rooms where smoking occurs, an individual might actually be more heavily exposed to ETS (in terms of particulate matter, specifically) by moving from the smoking to the "no smoking" area. Our results suggest that regulations to permit licensed clubs, taverns, and casinos to permit patrons to smoke in certain parts of the premises if smoking is barred in other parts, must be regarded as ineffective in protecting individuals at risk of passive smoking. The evidence presently available indicates that banning smoking on the premises is the only viable option to prevent exposure to ETS and this option is being adopted in a progressively increasing number of centres. Finally, recovery of damages as a result of a failure to prevent exposure to ETS is now recognised. The present report would suggest that designation of "no smoking" in certain arbitrary areas cannot be raised as an adequate response to the hazard presented by passive smoking.

\section{ACKNOWLEDGEMENTS}

This study was supported in part by a grant from Cancer Council NSW. The authors are grateful for the assistance provided by management in the various clubs whose facilities provided the basis of our investigation. The authors are grateful to Dr Valerie Delpech (now Medical Epidemiologist, NSW Health) for discussion of the design of the study.

\section{Authors' affiliations}

T Cains, S Cannata, R Poulos*, M J Ferson*, B W Stewartt, South East Sydney Public Health Unit, Randwick, NSW, Australia

*Also School of Public Health and Community Medicine, University of New South Wales, Sydney, NSW, Australia

†Also School of Women's and Children's Health, University of New South Wales

\section{REFERENCES}

1 Repace JL, Lowrey $\mathrm{AH}$. Indoor air pollution, tobacco smoke, and public health. Science 1980;208:464-72.

2 Taylor R, Cumming R, Woodward A, et al. Passive smoking and lung cancer: a cumulative meta-analysis. Aust N Z J Public Health 2001 ;25:203-11.

3 Hoffmann D, Wynder EL. Active and passive smoking. In: Marquardt $\mathrm{H}$, Schafer SG, McClellan R, Welsch F, eds. Toxicology. San Diego: Academic Press, 1999:879-98.

4 Law MR, Hackshaw AK. Environmental tobacco smoke. Br Med Bull 1996;52:22-34.

5 Daynard R. Why tobacco litigation? Tobacco Control 2003;12:1-2.

6 Stewart BW, Semmler PCB. Sharp v Port Kembla RSL Club: establishing causation of laryngeal cancer by environmental tobacco smoke. Med J Aust 2002; 176: 113-6.

7 Maskarinec MP, Jenkins RA, Counts RW, et al. Determination of exposure to environmental tobacco smoke in restaurant and tavern workers in one US city. $J$ Expo Anal Environ Epidemiol 2000;10:36-49.

8 Yamato $\mathrm{H}$, Seto T, Hori H, Higashi T, et al. [The effective smoking corner in an office]. Sangyo Eiseigaku Zasshi 2000;42:1-5.

9 Hammond SK, Sorensen G, Youngstrom R, et al. Occupational exposure to environmental tobacco smoke. JAMA 1995;274:956-60.

10 Lambert WE, Samet JM, Spengler JD. Environmental tobacco smoke concentrations in no-smoking and smoking sections of restaurants. Am J Public Health 1993;83:1339-41.

11 Braver M, Mannetje A. Restaurant smoking restrictions and environmental tobacco smoke exposure. Am J Public Health 1998;88:1834-6.

12 International Agency for Research on Cancer. Monographs on the Evaluation of Carcinogenic Risks to Humans. Volume 38: Tobacco smoking. Lyon: International Agency for Research on Cancer, 1986.

13 Ayers GP, Selleck PW, Gillett RW, et al. Determination of nicotine in water by gradient ion chromatography. J Chromatogr A 1998;824:241-5.

14 Bates MN, Fawcett J, Dickson S, et al. Exposure of hospitality workers to environmental tobacco smoke. Tobacco Control 2002;11:125-9.

15 International Agency for Research on Cancer. IARC Monographs on the Evaluation of Carcinogenic Risks to Humans. Volume 83. Tobacco smoke and involuntary smoking. Lyon: International Agency for Reserch on Cancer (in press).

16 Groten P, Cassee FR, Van Bladeren PJ, et al. Mixtures. In: Marquardt H, Schafer SG, McClellan R, Welsch F, eds. Toxicology. San Diego: Academic Press, 1999:257-70.

17 Walsh RA, Tzelepis F. Support for smoking restrictions in bars and gaming areas: review of Australian studies. Aust N Z J Public Health 2003;27:310-22. 